Fecha de recepción: 2 de enero de 2019 Fecha de aceptación: 12 de marzo de 2019

SUMARIO: I. Nota metodológica. II. Introducción. III. Las bases del utilitarismo. Iv. El utilitarismo: una corriente muy versátil y algunas de sus objeciones. v. Aclarando la universalidad y absolutismo de los derechos humanos (ningún derecho es absoluto). vi. ¿Es posible conciliar la idea del utilitarismo con los derechos humanos? vir. la propuesta de John Stuart Mill respecto a la justicia y los derechos. viI. El utilitarismo como medio para solucionar los conflictos normativos a nivel constitucional. Ix. Conclusiones de un no escéptico a la conciliación del utilitarismo y los derechos humanos. x. Bibliografía.

\title{
Resumen
}

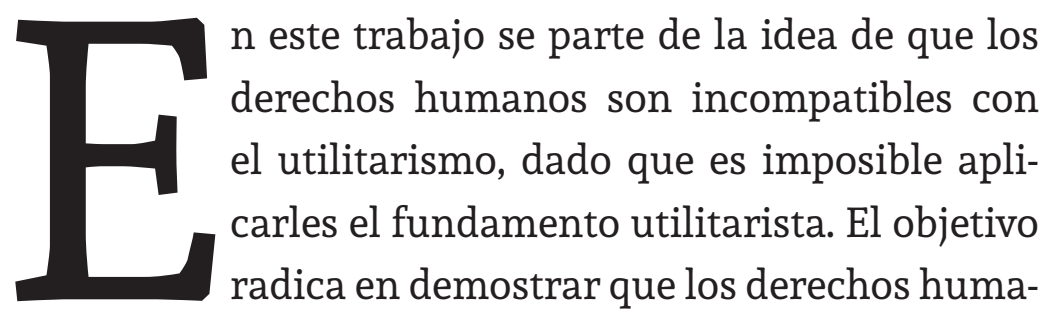
nos y el utilitarismo no se encuentran reducidos a un binomio indefectiblemente separable, como puede vislumbrarse prima facie. Para lograr lo anterior, se estudia si la postura utilitarista es realmente divergente con la teoría y la aplicación práctica de los derechos humanos. En consecuencia, se explora en qué condiciones es

1 Doctor en Derecho por la Universidad Autónoma de Chiapas (UNACH). Jefe del Departamento de Apoyo a la Comisión Intersecretarial para la Adquisición de Terrenos y Bienes en el Estado de Chiapas. Maestro en Derecho por la Universidad Nacional Autónoma de México. Especialista en Derecho Internacional Privado graduado con Mención Honorífica. Licenciado en Derecho por la UnACH. 
posible desplazar un derecho humano en favor de otro; asimismo, se considera si los defensores de los derechos humanos toman en cuenta la felicidad o el bienestar de las personas al elegir un derecho sobre otro. Para esto, es necesario examinar el fundamento para resolver los erróneamente llamados conflictos normativos, los cuales surgen en el nivel jerárquico de los derechos fundamentales. Al final, se expone una conclusión profunda que no solo se reduce a enunciar la posibilidad de conciliar el utilitarismo con los derechos humanos, sino que es mucho más expansiva, toda vez que no solo resulta útil sino imposible dejar de aplicarla; así, el permitir decidir con bases utilitarias en materia de conflictos entre los derechos humanos lleva como resultado que sea posible asociarlos con la doctrina ética de marras.

Palabras clave: derechos humanos, utilitarismo, conflictos, ponderación, felicidad.

\title{
Utilitarianism and human rights: an irreductible separa- ble binomial?
}

\begin{abstract}
This work is based on the idea that human rights are incompatible with utilitarianism since it is impossible to apply them to the utilitarian basis. The objective is to demonstrate that human rights and utilitarianism are not reduced to an unfailingly separable binomial as can be seen at first sight. To achieve the above, it is studied if the utilitarian position is really divergent with the theory and the practical application of human rights. In consequence, it is explored in what conditions it is possible to displace a human right in favor of another; it is also considered if the defenders of the human rights take into account the happiness or well-being of people when choosing one right instead of another. For this it is necessary to examine the basis to resolve the erroneous-
\end{abstract}


ly called normative conflicts which arise at the hierarchical level of fundamental rights. At the end a profound conclusion not only stated the possibility of reconciling utilitarianism with human rights, but it is much more expansive, since it is not only useful but impossible to stop applying it; thus, allowing to decide with utilitarian bases regarding conflicts between human rights results in the possibility of associating them with the ethical doctrine already enunciated.

Keywords: human rights, utilitarianism, conflicts, weighing, happiness.

\section{Nota metodológica}

La investigación es de corte cualitativo, toda vez que, a partir de cierta información obtenida a través de la técnica bibliográfica documental, se generan datos necesarios para lograr las conclusiones; es decir, en el presente trabajo se realizó un enfoque que privilegia la comprensión y la interpretación de la información obtenida, para llegar a la conclusión de si es posible o no conciliar la Teoría utilitarista con los derechos humanos (DD. HH.).

El método a utilizar dentro de la presente investigación es deductivo, debido a que el análisis de una premisa general basada en que es imposible asociar la corriente utilitarista con los DD. HH. y a través de la metodología empleada, permitirá llegar a un postulado particular dentro de la investigación, que es establecer que dicha disonancia es tan solo aparente y que no únicamente es posible sino que tiene una relevancia práctica.

Es pertinente aclarar que, para lograr la consecución del presente artículo, nos situamos en el contexto paradigmático de algunos autores como Laporta y González Amuchastegui (2004), quienes enuncian que los DD. HH. son absolutos. Así, partiendo de este enfoque teórico es posible realizar el estudio correspondiente, para enunciar si se puede conciliar la postura utilitarista con la visión paradigmática que acabamos de mencionar respecto a los DD. HH.

Por lo que primeramente para lograr lo anterior, es necesario sentar las bases del utilitarismo y plantear algunas objeciones a dicha corriente ética, así como también abordar la supuesta universalidad y absolutismo de los DD. HH. A partir de este punto seremos capaces de abordar el estudio correspondiente, que comprende si es posible conciliar los DD. HH. con la postura utilitarista. Por último, se abordará que el utilitarismo es utilizado para resolver los llamados conflictos normativos a nivel constitucional.

\section{Introducción}

"Exceptio probat regulam in casibus non exceptis".

Es conocido que los DD. HH. gozan de ciertas características. Entre estas, se encuen- 
tran las de universalidad e inalienabilidad; incluso algunos autores han tenido los arrojos al sostener que son absolutos; ${ }^{2}$ la propuesta del utilitarismo es muy simple: maximizar la felicidad general y procurar que los placeres (en la especie que nos interesa, los derechos, también se traduce en placeres, felicidad y bienestar) sean disfrutados por todas las personas, si es posible; si no, al menos por el mayor número de estas.

Es incontrovertible y lógico asentir al leer o escuchar algunas manifestaciones, como que se deben asegurar los derechos de las personas; que nadie será objeto de cálculos utilitaristas sin freno; que ninguna minoría sufra el detrimento del goce de sus derechos en beneficio de una mayoría. Realizar lo anterior conllevaría a ir en contra del principio de universalidad e igualdad de los derechos, el cual se encuentra consagrado constitucionalmente en el artículo primero de nuestro pacto federal.

Dicho lo anterior, se expresaría que el utilitarismo y los DD. HH. son disímbolos

2 Existe una teoría en donde se conciben los derechos como absolutos, entre otras características. De estandarte podemos tomar a González Amuchástegui, quien menciona que los DD. HH. son absolutos. Con tal afirmación, se quiere dar a entender que se vence en todos los casos en los que se enfrente con otras pretensiones. El autor que tomamos como ejemplo menciona su idea acerca de los derechos que "no pueden ser desplazados en ninguna circunstancia y por ninguna otra consideración moral". Cfr. González Amuchastegui, Jesús, Autonomía, dignidad y ciudadanía: una teoría de los derechos humanos, España, Tirant Lo Blanch, 2004, pág. 356. y que cada uno se orienta en direcciones contrarias; de esto cabe siempre aplicar la duda metódica de René Descartes, por lo que cabe plantearse la siguiente pregunta: ¿puede conciliarse la corriente del utilitarismo con los DD. HH.?

Prima facie, la respuesta sin mayor análisis sería negativa y la razón es porque los DD. HH. deben ser aplicados para todas las personas, a diferencia del resultado que devendría si se empleara la corriente utilitarista, toda vez que los DD. HH. se aplicarían a través de cálculos cuantitativos.

Así, ¿podría alguien con tendencia utilitarista mantenerse fiel a sus principios y, a la vez, respetar los DD. HH.?, ¿en un Estado garantista recurrimos a poner en la balanza ciertos derechos elevados a DD. HH.?, ¿es correcto ponderar/considerar un/unos derecho/s sobre otro/s? Las interrogantes anteriores serán resueltas a lo largo del presente artículo y se visualizarán en las conclusiones.

\section{Las bases del utilitarismo}

El utilitarismo aparece en los siglos xviII con Jeremy Bentham (1748-1832) y xix con John Stuart Mill (1806-1873), pero el propio Bentham reconocía que el principio básico de su filosofía provenía de los ilustrados Claude-Adrien Helvétius ${ }^{3}$ y César Beccaria

3 Claude-Adrien Helvétius fue un filósofo, filántropo y recaudador de impuestos ilustrado suizo-francés. El tratado de Helvétius, De l'ésprit (1758), influyó en Cesare Beccaria, y a través de este, los utilitaristas ingleses. La definición de Helvétius de bienestar so- 
(1988). ${ }^{4}$ El término utilitarismo se debe a que Bentham denominó utilidad a la propiedad de cualquier objeto de producir beneficio, ventaja, placer o utilidad. En este sentido, la utilidad es considerada como el valor supremo y norma de conducta a los que está sometido cualquier otro deber, norma o valor. ${ }^{5}$

No se debería pecar de ingenuos y obviamente si se presta atención a las bases del utilitarismo, esta es una especie de la teoría ética denominada consecuencialista. Como ya indicamos, el utilitarismo es una teoría ética que fue propuesta por Jeremy Bentham, quien enunció el principio de numeración de la felicidad: "Rule: In case of collision and contest, happiness of each party being equal, prefer the happiness of the greater to that of the lesser number" ${ }^{6}$

cial como la "mayor felicidad del mayor número" anticipó el "principio de mayor felicidad" de Jeremy Bentham del utilitarismo clásico. Karl Marx, incluso, afirmó que Bentham “...simplemente reprodujo de manera aburrida lo que Helvétius y otros franceses habían dicho con ingenio e ingenio en el siglo XVIII”. Cfr. Karl Marx, Capital (trad.: Ben Fowkes), England, Penguin Classics, 1976, pág. 758.

4 Beccaria dotó de gran importancia a la búsqueda de la felicidad de la colectividad y que la legislación debería ser el medio para lograr dicho objetivo como aspecto fundamental. Beccaria dijo: "La felicidad dividida entre el mayor número deberá ser el punto a cuyo centro se dirigiesen las acciones de la muchedumbre”. Cfr. Beccaria, César, De los delitos y las penas (trad.: Juan Antonio de las Casas), Madrid, Editorial Alianza, 1988, pág. 26.

5 Cfr. Ibidem, pág. 8.

6 Traducción personal: "Regla: En caso de colisión y disputa, la felicidad de cada parte siendo igual, prefiere la felicidad de la mayor a la de la menor". Véase: Bentham, J., The Philosophy of Economic Science/ The Psychology of Economic Man, London, The Royal Economic Society by George Allen \& Unwin Ltd., págs. 91-92.
Bentham define la felicidad de la siguiente manera:

In so far as the sum of the pleasures of all kinds, experienced by the person in question, during the length of time in question, is regarded, as considerable, -the sum of the pains of all kinds experienced by him during that same length of time, being, moreover laid out of the account, -the state which in that respect he is regarded as being in, is termed as state of happiness. ${ }^{7}$

Como podemos apreciar en el principio de numeración de la felicidad, Bentham concibió que esta era imposible de ser realizable para todos, porque la felicidad de cada individuo puede entrar en conflicto con la de otros, por lo que la felicidad de uno de ellos podrá lograr una disminución en la felicidad de otro. En consecuencia, la dificultad de garantizar la felicidad de todos lleva a Bentham a reflexionar como objetivo universal la consecución no de la mayor felicidad de todos, sino del mayor número.

7 Traducción personal: "En la medida en que la suma de los placeres de todo tipo, experimentados por la persona en cuestión, durante el tiempo en cuestión, es considerable - la suma de los dolores de todo tipo experimentados por él durante esa misma duración de tiempo, además de estar expuesto en la cuenta- el estado en el que se considera que se encuentra al respecto, se denomina estado de felicidad”. Véase: Bentham, Jeremy, The Works of Jeremy Bentham, Vol. vIII, Scotland/London, Simpkin, Marshall \& Co., 1843, pág. 82. 
La propuesta del utilitarismo ha sido caricaturizada de esta manera: "maximizar la felicidad general”, procurar que los placeres sean disfrutados por todas las personas si es posible, y si lo anterior es imposible, al menos tratar de que sea compartido por el mayor número de individuos. Esta corriente afirma que se debe procurar la felicidad para el mayor número de personas. En otras palabras, parte de la idea de que la felicidad del mayor número es la que debe imperar, y si en ello se perjudica a algún/ os individuo/s, puede ser aceptable en aras de propiciar un beneficio mayor para un número mayor de personas, sin importar que sea en detrimento de otra/s.

El utilitarismo es una corriente ética que encaja entre las teorías del placer y la felicidad. Las teorías cognitivistas mencionan qué tan buena es una propiedad o cualidad y, por tanto, la oración "X es bueno" es descriptiva, la cual será verdadera o falsa, según X sea realmente bueno o no. ${ }^{8}$

Sin entrar en mayores disquisiciones sobre qué es la ética — toda vez que no es el propósito de este paper-, se considera en este trabajo a la ética como una rama de la filosofía que se encarga de delimitar los actos virtuosos o deshonrosos enmarcados dentro del ámbito espacial y temporal de una cultura; por lo que lo éticamente "bueno" o "malo" desde esta corriente éti-

8 Varó Peral, Āngels, Algunas teorías éticas occidentales, pág. 3 (https://www.nodo50.org/ filosofem/IMG/pdf/etica4c.pdf); fecha de consulta: 12 de mayo de 2018. ca, es decir, la utilitarista, será la conducta que consiga mayores beneficios con menores perjuicios; dicho de otro modo, la felicidad general (general happiness). En síntesis, desde la óptica de esta teoría, un juicio moral versa o trata acerca de la felicidad, y una acción es buena o mala en la medida en que conduzca a la prosperidad o desventura de la colectividad.

Desde la óptica de esta teoría, aquellas acciones que tiendan a incrementar el bienestar serán llamadas buenas, y aquellas que tendieran a incrementar la desdicha, malas; en consecuencia, emitiremos un juicio moral sobre lo bueno y lo malo de una acción que desembocará en felicidad o desventura. Lo anterior ya lo ha manifestado con anterioridad y certeza Andrea Valcarce:

[...]al comparar las cualidades morales de las acciones[...]somos guiados por nuestro sentido moral de la virtud a juzgar así; [...] de tal modo que una acción es la mejor, cuando procura la mayor felicidad para el mayor número; y la peor, cuando, de la misma manera, ocasiona sufrimiento. ${ }^{9}$

La felicidad es entendida como un mayor bienestar o satisfacción de las necesidades. Afirmar en este sentido que " $\mathrm{X}$ es

9 Valcarce, Andrea, El utilitarismo y la Teoría moral de Adam Smith, Revista Empresa y Humanismo, vol. XIII, núm. 10, pág. 271 (https://goo.gl/m8hnJS); fecha de consulta: 1 de febrero de 2019. 
bueno" equivale a decir que " $\mathrm{X}$ produce bienestar". El fundamento de justificación de esta teoría para decir que todas las personas "deben hacer X" o expresar juicios de valor como "que algo es bueno o malo", depende del bienestar.

Al hilo de lo manifestado en los párrafos que preceden, para los utilitaristas no hay juicios de valor de bueno o malo respecto a las conductas o las reglas o normas; un deber o un valor; lo bueno o malo dependerá del cálculo de las consecuencias en términos de beneficios y perjuicios para los placeres, bienes o intereses en juego.

\section{El utilitarismo: una corriente muy versátil y algunas de sus objeciones}

Podemos reducir el utilitarismo de John Stuart Mill como aquella teoría filosófica tendiente a procurar la mayor felicidad posible a los seres humanos, evitándoles pena o dolor. La búsqueda de la felicidad común viene, entonces, a constituirse en la piedra angular de esta corriente filosófica. El utilitarismo puede ser aplicado en diferentes campos del conocimiento, como el económico y del derecho.

El utilitarismo parte de una visión egoísta en la que el hombre siempre actúa movido por sus propios intereses, que se manifiestan en la búsqueda del placer y en evitar el dolor. Alguna de las objeciones que se le reprochan al utilitarismo, es que las personas carecen de importancia en lo individual y que solo tienen un valor respecto a la contribución que hagan para poder brindar felicidad a todos los miembros de la sociedad en conjunto.

La crítica anterior que se le hace al utilitarismo consideramos que radica en que los individuos son concebidos de tal manera que se tiende a cosificar a las personas para que sean utilizadas para un fin. En consecuencia, fungen como un medio para lograr el fin de la felicidad de la sociedad en conjunto; ya no se ve al individuo como un fin en sí mismo, como lo enunció Kant $^{10}$ en su segundo imperativo categórico, sino como un medio para la satisfacción en mayor proporción.

El utilitarismo antes mencionado entra en la clasificación de las posturas utilitaristas; en específico, es un utilitarismo positivo, que se refiere a la potenciación de lo bueno, de la felicidad. También es posible desde la lógica y argumentando a contrario sensu deducir que existe un utilitarismo negativo, el cual básicamente tiende a tratar de reducir lo malo, lo negativo, por lo que, en consecuencia, se transformará en mayor bienestar y felicidad. De lo anterior claramente estamos violando el concepto de dignidad humana de las personas.

Otro dardo en contra del utilitarismo consiste en que existen demasiadas posturas utilitaristas; lo anterior es cierto, pero

10 Afirma Kant que el hombre es un fin en sí mismo, no un medio para usos de otros individuos, lo que lo convertiría en una cosa, por lo que se vulnera la dignidad del hombre si es utilizado como un medio, pues el hombre es un fin en sí mismo. 
podemos hacer mención de dos posturas utilitaristas importantes que nos servirán para desarrollar el presente estudio: el utilitarismo de actos y el utilitarismo de reglas, que tienen que ver con aquello que posee la capacidad para producir felicidad:

1. El utilitarismo de actos básicamente se centra en juzgar las consecuencias del acto o comportamiento.

2. El utilitarismo de reglas es la teoría para la cual lo correcto o incorrecto de una acción, debe ser sopesado por la bondad o maldad de las consecuencias de una ley. Siendo a una ley o norma, por consiguiente, a la que cada uno debe adecuar sus acciones en tales circunstancias, y esta será buena si de su observancia y aplicación deviene un mayor bienestar general.

\section{v. Aclarando la universalidad y absolu- tismo de los derechos humanos (ningún derecho es absoluto)}

¿Qué pretende la afirmación respecto a que los DD. HH. son universales y absolutos? Tales características mencionadas anteriormente son necesarias en la medida en que los DD. HH., de manera preventiva, deben proteger a los seres humanos en todas las ocasiones, al menos en una concepción a priori.

Es por esto que una motivación para que esta clase de derechos sea en general, es para evitar que se apliquen medidas utilitaristas, es decir, evitar que una minoría sufra para que una mayoría salga beneficiada. Si algo tiene la capacidad de estar en medio del gobierno o de las sociedades sacrificando derechos a expensas de grupos minoritarios para el beneficio de la colectividad, estos deben ser los DD. HH.

Lo anterior así lo afirma González Amuchastegui (2004): "La característica común a todos los derechos humanos es que son concebidos como límites infranqueables incluso para las mayorías" ${ }^{11}$

Es por eso que se indica que los DD. HH. son "[...] inherentes a todos los seres humanos, sin distinción alguna de nacionalidad, lugar de residencia, sexo, origen nacional o étnico, color, religión, lengua, o cualquier otra condición. Todos tenemos los mismos derechos humanos, sin discriminación alguna". ${ }^{2}$

Existen algunas críticas referentes a la universalidad, ${ }^{13}$ que ya han sido plantea-

11 González Amuchastegui, Jesús, op. cit., pág. 355.

12 Cfr. http://www.ohchr.org/SP/Issues/Pages/WhatareHumanRights.aspx; fecha de consulta: 1 de febrero de 2019.

13 El autor Jesús González Amuchástegui las ha resumido de la siguiente manera:

a) No respeta la pluralidad moral y cultural existente en el planeta, supone una actitud incompatible con la tolerancia preconizada por la propia ética liberal, y refleja una tentación imperialista muy presente en el Occidente; b) La segunda gran crítica que se dirige al universalismo tiene dos objetivos: la noción de individuo como agente moral racional y la creencia en la posibilidad de construir mediante la razón y el diálogo con los demás individuos-agentes morales racionales un código moral ex novo válido para todos los potenciales participantes en ese diálogo, es decir, la humanidad entera; c) Descansa en una concepción individualista que olvida la di- 
das con anterioridad, pero en esta ocasión obviaremos detenernos a analizar cada una de ellas, toda vez que no son parte del presente trabajo; pero con su mención queremos dejar en claro que no somos los primeros y mucho menos los últimos que formulan y formularán esta cuestión, dejando en claro que la finalidad es tratar de superar dicha problemática y tratar de entender el porqué de esa categorización a los DD. HH.

Cuando hablamos de los DD. HH. como universales, se está haciendo referencia a que "[...]por un lado, constituyen un paradigma moral válido en todo el mundo, y por otro, reconocen a todos los seres humanos su condición de sujetos de esos sistemas normativos de validez universal”. ${ }^{14}$ La anterior afirmación significa que tajantemente consta una sola moral legítima para todos, que es fruto de la razón (es descubierta por la razón) e instaura que todos los seres humanos son titulares de tales derechos.

Por un derecho absoluto como característica que distingue a los DD. HH., entendemos aquel que jamás puede ser negado. Es difícil argumentar que un derecho es

mensión colectiva, los vínculos comunitarios en la noción de individuo, y en consecuencia no otorga relevancia al tercer elemento de la trilogía revolucionaria de 1789 - la fraternidad-, y niega la existencia de derechos de carácter colectivo. Para ver más de este tema, se puede consultar el artículo de González Amuchastegui, Jesús, ¿Son los derechos humanos universales?

14 González Amuchastegui, Jesús, op. cit., nota 3, pág. 346. absoluto si los beneficios que imparte pueden ser disfrutados en grados; verbigratia, la libertad es un ejemplo clásico de un derecho que permite aumentos y disminuciones relativos en su posesión y ejercicio.

El análisis se torna problemático al saber que la mayoría de los derechos, desde el punto de vista como prerrogativas o concesiones, se ejercen o disfrutan en grados. Por lo tanto, se hace imposible afirmar que todos los DD. HH. son absolutos. Sin embargo, se puede sugerir que, al menos, un derecho o unos cuantos deberían ser absolutos, o al menos deberían serlo, y este es el derecho a la vida, ya que ningún otro derecho humano puede ser relevante si la vida puede ser tomada a discreción por cualquier individuo.

Iñigo Álvarez (2014) está de acuerdo con la afirmación que se realizó anteriormente, pero la resume de una manera lacónica y magistral: "[...]lo cual no deja de ser discutible, pues el término 'absoluto' no indica una propiedad gradual y, en consecuencia, es difícil que algo sea 'un poco absoluto'[...]”. ${ }^{15}$

Existen algunas posturas que tratan de defender el carácter de absoluto y relativo al mismo tiempo, pero lo anterior rompe con uno de los principios de la lógica formal, como el principio de la no contradic-

15 Álvarez Gálvez, Íñigo, Universales, absolutos e inalienables: los derechos indestructibles, Revista de Humanidades de Valparaíso, año 2, núm. 4, 2014, pág. 66 (https://goo.gl/k1dxtj); fecha de consulta: 1 de febrero de 2019. 
ción, el cual afirma que una proposición y su negación no pueden ser -ambasverdaderas al mismo tiempo y en el mismo sentido. ${ }^{16}$

Santamaría González (2016) menciona que los DD. HH. pueden defender, a la vez, su carácter absoluto y relativo, pero en el sentido de que son relativos en relación con la interdependencia, la interrelacionalidad que existe entre un derecho humano y otro; ${ }^{17}$ consideramos que lo anterior es un artífice para escapar de la verdadera naturaleza de la relatividad, porque todo lo que sea relativo no puede ser absoluto, es decir, que carezca de condicionantes o circunstancias que puedan alterar su esencia, por lo que los DD. HH. serían absolutos si realmente pudieran prevalecer en cualquier situación, pero sabemos que existen condiciones que apremian que estos sean prescindibles.

En conclusión, los DD. HH. carecen del absolutismo que se les atribuye, toda vez que desde ciertas condiciones o circunstancias son vencidos o no respetados, por lo que lo mejor sería llamarlos derechos con características prioritarias o relevantes.

16 Audi, Robert, The Cambridge Dictionary of Philosophy, England, $2^{\text {nd }}$ Ed., Cambridge University Press, 1999, pág. 737.

17 Lo anterior lo ejemplifica Isabel Santamaría: “[...]El ejercicio de un derecho facilita el ejercicio de los demás. El derecho a la educación garantiza la libertad de pensamiento. De la misma manera, la privación de un derecho afecta negativamente a los demás, si se niega el derecho a la educación está afectando a la libertad de pensamiento". Cfr. Santamaría González, Isabel, Agentes de la escala básica, España, Rodio Ediciones, 2016, pág. 13.

\section{VI. ¿Es posible conciliar la idea del utilitarismo con los derechos humanos?}

[...], ni tenéis en cuenta que os es más conveniente que un hombre muera por el pueblo, y no que toda la nación perezca.

Juan 11:50.

Partiendo del punto de apoyo de que los DD. HH. se encuentran basados en nuestros sentimientos y profundas creencias de que son buenos, cabe recordar también que estos sentimientos no han surgido en el vacío, ${ }^{18}$ sino que se han adquirido a través del tiempo y de conquistas sociales, pues, como muestra la historia, las violaciones a los DD. HH. tienen consecuencias horrorosas.

A partir de la censura y otro tipo de restricciones que se implementan en una sociedad, de estas actividades es más probable que se susciten cambios indispensables en las comunidades que las practican, con la finalidad de abolirlas y evitarlas.

Jeremy Bentham, padre y creador del utilitarismo, parte del rechazo de la idea de concebir a los DD. HH. como naturales, por lo que criticó dicha idea y calificó como un sinsentido la afirmación de que existen derechos previos al Estado; para Bentham, los derechos -en caso de existir- son un producto social que se justifica desde el principio de la utilidad.

18 Uno de los temas que siempre ha estado presente, y que consideramos no debería ser de mayor trascendencia, es el de los fundamentos de los DD. HH. 
Los primeros utilitaristas como Bentham ${ }^{19} y$ Mill estaban interesados en grandes reformas sociales que formularon cuando se opusieron a la esclavitud, cuando defendieron los derechos de las mujeres, trabajadores y homosexuales, así como cuando abogaron por la educación universal, la libertad de prensa y del comercio.

Como economistas y filósofos, su gran aportación fue desarrollar un método para reflexionar sobre cómo querían que fuese la sociedad sin apelar a principios sagrados como la tradición o el mandato religioso, que simplemente se aceptan y encierran ya una respuesta inamovible e innegociable.

En este tenor, cabe formular si los beneficios que puede otorgar la tortura son insignificantes en comparación con el sufrimiento que inflige y el daño a la sociedad. Debido a la falibilidad de la naturaleza humana y la naturaleza especial de los DD. HH., las reducciones de estos causan un peligro inaceptable para la colectividad.

Por ejemplo, permitir que el gobierno realice una lotería para las donaciones forzadas de órganos presentaría un peligro inaceptable de abuso, ya que la autoridad podría inmolar a cualquier persona falsificando los resultados de tal lotería.

19 Fue este el punto de partida desde el que Bentham llevaría a cabo una permanente y activa crítica de los usos y costumbres de su tiempo, de sus instituciones, abogando por la discriminación de la homosexualidad, la extensión del sufragio universal, las reformas de las administraciones públicas, del sistema de prisiones o del bienestar de los animales.
Son tales los abusos cometidos en el pasado, así como asesinatos sin sentido patrocinados por el gobierno por un supuesto bien público los que causan una aversión subconsciente.

¿Por qué es deleznable actualmente la institución de la esclavitud? Plantearnos esta pregunta actualmente en sociedades occidentales parece ser bastante superfluo y perogrullesco, debido a que cualquier persona podría responder llana y simplemente que la libertad es un derecho humano fundamental y aceptado; un logro en el progreso moral de las comunidades. La profesora Guisán (2000) diría: "las consideraciones de bienestar general no pueden sobrepujar el valor de los 'derechos' de los individuos". ${ }^{20}$

Para Bentham y Mill, desde la óptica de la utilidad, la esclavitud no es buena o mala porque Dios lo diga, es mala porque vivimos peor con ella que sin ella; claro que es innegable que la mayoría puede lograr vivir mejor a costa o en perjuicio de otro, pero su mayor felicidad no compensa la desgracia de los esclavos. Para este primer utilitarismo, la felicidad y desgracia de cada uno sería medible y bastaría sumarlas para decidir qué situación es mejor.

El utilitarismo negativo, como ya se menciona, tiende a tratar de reducir lo negativo y, en consecuencia, se transformará en mayor bienestar y felicidad. Fijémonos

20 Guisán, E., Más allá de la democracia, Madrid, Tecnos, 2000, pág. 106. 
que si se acepta este utilitarismo todos estaremos de acuerdo en qué es mejor y qué es peor, puesto que todos realizaremos el mismo cálculo.

Desde el argumento planteado en el párrafo anterior, se opone la posibilidad de que haciendo las sumas, la mayor utilidad agregada ocurriera en la sociedad esclavista, pero los utilitaristas responderían que no somos hormigas y valoramos la libertad, y que, por tanto, la suma forzosamente de la infelicidad ha de ser peor en la comunidad esclavista; por lo tanto, tener miedo de este criterio equivaldría a no tener confianza en nuestra propia naturaleza.

Consideramos que ese presupuesto que planteaban Bentham y Mill, parece no ser moral o de principios, sino antropológico. Guisán (2000) comenta que: "Somos 'por naturaleza' seres tendentes a la libertad y que llevamos mal las desigualdades y es por ello por lo que la libertad y la igualdad relativa se convierten en bienes irrenunciables". ${ }^{21}$ Además, "es siempre la referencia al bienestar humano privado y colectivo lo que es 'trump' sobre otro tipo de consideraciones, incluidos los derechos y los privilegios". 22

Como sabemos, la deontología es la teoría ética normativa en la cual existen ciertas acciones que se deben realizar, y

21 Citado por Rodríguez-Toubes Muñiz, Joaquín, La utilidad de los derechos humanos, Revista Iberoamericana de Estudios Utilitaristas, vol. 17, núm. 2, 2010, pág. 120. otras que no se deben llevar a cabo, más allá de las consecuencias positivas o negativas que puedan traer. Si nos fijamos en la deontología kantiana, consideramos que esta concibe a un ser humano equiparable a un robot; a manera de ejemplo, para el filósofo de Königsberg el deber de decir siempre la verdad o de no mentir, es una ley moral inviolable, pero digamos que un ladrón irrumpe en un domicilio y pregunta: “¿dónde está tu madre?”, ¿acaso le responderían con la alta posibilidad de que la lastime y, en el peor de los extremos, la asesine?, ¿es incorrecto mentir para salvaguardar su vida?

Si nos mantenemos en la postura radical mencionada en el párrafo anterior de que hay que hacer lo que se ordena o es debidamente correcto hacer sin importar las consecuencias, entonces lo correcto sería decirle al ladrón donde está la madre sin importar que puedan arrebatarle la vida. Como podemos apreciar, de ser así también nos estaríamos convirtiendo en un adorador de un imperativo moral a ultranza, pero en la actualidad las éticas deontológicas se han humanizado y vuelto más sensibles.

Las posturas modernas logran conciliar la infracción de un deber si con esta acción se logra obtener una consecuencia favorable de dicha acción. En el ejemplo que se exteriorizó en los párrafos anteriores y del cual seguimos en esa línea argumentativa, si es posible salvar una vida hu- 
mana infringiendo el postulado de decir siempre la verdad, un ético deontológico puede reconocer una ponderación de los resultados de la acción. No obstante, en estos casos, se toman en cuenta las consecuencias de la acción y no el valor propio de la acción, por lo que queda suspendida la deontología.

De lo anterior podemos mencionar que la deontología queda suspendida y volvemos a un utilitarismo de actos; como ya es conocido, el act utilitarianism asevera que el acto de una persona es moralmente correcto si, y solo, produce los mejores resultados posibles en esa situación específica.

En algunos pasajes, la profesora Guisán (2000) parece acoger un enfoque, el cual creemos que es deontológico, ya que la filósofa menciona:

Cuando está claro que unos bienes son superiores a otros en lo que a la producción del goce profundo y solidario se refiere, las consideraciones cuantitativas son irrelevantes. Una sola persona feliz en su libertad es preferible a un millón de seres felices en su esclavitud o su servidumbre. ${ }^{23}$

En los tiempos en que la esclavitud era legal y aceptada por gran parte de la población, la lucha contra ella no podía apelar a esos sentimientos morales, por lo menos, no solo a ellos. Había gente a quien

23 Idem. le repugnaba la idea de la esclavitud y a otros les agradaba. Una disputa sobre la esclavitud fundada en preferencias morales no tiene, en estos términos, buenas maneras de establecer un terreno común en el cual dirimir las diferencias y llegar a algún tipo de acuerdo.

Tanto los detractores como los defensores defendían sus ideas apelando a principios; en el mundo occidental, unos y otros encontraban en la religión y en la Biblia principios absolutos de los cuales deducir su postura. Los beneficios utilitarios que se aplican a los DD. HH. coinciden con las razones principales por las que se han desarrollado los sentimientos hacia los mismos; a diferencia de la confianza en los sentimientos, el utilitarismo coloca a los DD. HH. en una base lógica sólida.

El razonamiento utilitario excluye las creencias tradicionales y las diferencias culturales, las cuales en lugar de resolver los dilemas los agravan, ya que el utilitarismo se basa en el positivismo, es decir, en lo que se observa o puede observarse a través de los sentidos. La intuición para los DD. HH. es frágil y muchas sociedades carecen de intuición; incluso, en Estados Unidos hoy en día existe el homicidio, patrocinado por el gobierno, de ciertas personas "indeseables" indefensas, es decir, la pena de muerte se considera aceptable.

Además, las instituciones erróneas pueden crear derechos ficticios, como el de los padres a golpear a sus hijos o, en el 
pasado, la institución de la esclavitud, que otorgaba el derecho de los dueños de esclavos a sus propiedades legalmente adquiridas, esclavos. ${ }^{24}$ Por lo tanto, el utilitarismo protege y realza los DD. HH., que son instrumentos útiles y legítimos, a fin de exigir la modificación o eliminación de instituciones y prácticas que los contradicen o lesionan.

Algunos autores mencionan que el utilitarismo de reglas sirve para conciliar la corriente utilitarista con la Teoría de los derechos humanos, por lo que podemos usar la siguiente conceptualización del utilitarismo de reglas:

In the rule utilitarism the attention is focused on the consequences of following the rules, in other words the question is which rule ought to be followed in order to get as much benefit as possible and on

24 Para Bentham y Mill, desde la óptica de la utilidad, la esclavitud no es buena o mala porque Dios lo diga, es mala porque vivimos peor con ella. Claro está que es innegable que unos cuantos viven mejor a costa o en perjuicio de otro, pero su mayor felicidad no compensa la desgracia de los esclavos. Según este primer utilitarismo, la felicidad y desgracia de cada uno sería medible y bastaría sumarlas para decidir qué situación es mejor. Nos debemos percatar que si se acepta este utilitarismo estaremos de acuerdo en qué es mejor y qué es peor, puesto que todos haremos las mismas cuentas utilitarias. A este argumento se opone la posibilidad de que, haciendo las sumas, la mayor utilidad agregada ocurriera en la sociedad esclavista. Los utilitaristas responden que no somos hormigas y valoramos la libertad, y que, por tanto, la suma forzosamente ha de dar como peor a la sociedad esclavista. Por tanto, tener miedo de este criterio equivaldría a no tener confianza en nuestra propia naturaleza. which grounds the rules to be followed are chosen..$^{25}$

El sustento de que se pueden conciliar los DD. HH. con el utilitarismo, se debe a que es conocido que estos fungen como valores morales y que la sociedad debe respetarlos de manera sucesiva, pero no solo eso: para que cobren plena eficacia, a la vez necesitan estar positivizados dentro del marco legal. De esta manera, al crear una conciencia de que los DD. HH. son parte del derecho, la felicidad en general es progresiva.

Retomando lo anterior, los DD. HH. solo pueden desenvolver su pleno vigor cuando se les garantiza a través de normas positivizadas, lo que lleva inherentemente a que sean aptos de ser garantizados bajo la tutela judicial por parte del Estado, quien no debe reconocerlos, sino protegerlos y garantizar su efectividad. De esta manera, la mayor felicidad de todos se alcanza gracias al respeto de los derechos de todos y cada uno de nosotros.

Así, estamos argumentando acerca de los derechos desde la guardia del principio de utilidad, partiendo de la premisa de que si existen positivizados, en conclusión, habrá una mayor felicidad.

25 Traducción personal: "En el utilitarismo de reglas, la atención se centra en las consecuencias de seguir las reglas; en otras palabras, la pregunta es qué regla se debe seguir para obtener el mayor beneficio posible y por qué motivo se eligen las reglas a seguir". 
También partimos de la premisa de que los derechos generan felicidad, pero no solo eso: es un requisito sine qua non que sean respetados para que se genere tal consecuencia. A la par de lo esgrimido, queremos hacer la salvedad de que estamos conscientes de que pueden existir casos de excepción.

Así, podemos argumentar y fundamentar la compatibilidad de los DD. HH. y el utilitarismo en dos propuestas:

1. Los DD. HH. resguardan bienes que mayoritariamente son preferidos a los demás u otros bienes hasta el punto de que, en caso de colisión entre ellos, lo mejor es respetar los DD. HH., lo cual causará más dicha que realizar lo contrario. Se trata de una hipótesis empírica, que viene a fundamentar la obligación moral de respetar los DD. HH. en la probabilidad de conseguir así la mayor utilidad. ${ }^{26}$

2. Un segundo desarrollo del argumento utilitarista en defensa de los DD. HH. arguye que estos protegen bienes tan preferibles a los demás, por lo que en

26 Existen críticas a tal desarrollo: hay un autor que ante tal postura tiene un problema, la cual desarrolla de la siguiente manera: "El problema de esta fundamentación es que no justifica la idea aceptada de derechos humanos, según la cual son una noción moral (y en su caso también jurídica) y no la proyección de un evento probable. No es propio de la idea de derechos humanos someter su existencia y respeto a la posibilidad, por improbable que resulte, de que pasarlos por alto produzca globalmente (computando los intereses del titular del derecho igual que los demás) mayor utilidad que respetarlos". caso de conflicto causa necesariamente más felicidad o bienestar respetar los derechos que perseguir los bienes enfrentados a ellos.

La crítica a esta postura puede devenir en que si lo bueno o malo (lo bueno traducido como felicidad y lo malo, como desdicha) depende de la consecuencia que produzca una norma (derechos), los estamos reduciendo a instrumentos aptos para que se reproduzca lo bueno; y peor aún, si las consecuencias son mejores a costa de que las reglas sean desobedecidas, entonces así debe ser: deben pasar por inadvertidas.

¿Qué podemos extraer de las anteriores manifestaciones? Puede concluirse lo siguiente:

1. La regla dejaría de existir como tal, toda vez que estas deben transmitir seguridad, es decir, saber en qué casos van a ser aplicadas y los casos de excepción, pero la seguridad que otorgan sería un supuesto diletante; pero al obrar de esa manera, la regla dejaría de existir como tal, pues como menciona Iñigo Álvarez (2009) “[...]nos estaríamos guiando por la utilidad de cada comportamiento y no por la utilidad de la clase de comportamiento estipulada en la regla”. ${ }^{27}$ Así, al permitirse los casos de excepción a la regla, entonces el utilitarismo

27 Álvarez Gálvez, İñigo, Utilitarismo y derechos humanos: la propuesta de John S. Mill, Madrid, csic/Plaza y Valdés, 2009, págs. 98 y 99. 
de reglas queda subordinado al utilitarismo de actos, pudiendo colegirse que el utilísimo de regla es una especie del utilitarismo de acto.

2. Entonces la crítica principal hacia el utilitarismo de reglas consiste en que sea una postura consistente y coherente. La objeción más común es que si se hace una excepción a la regla, porque exista un caso que tenga como mejor consecuencia el quebrantamiento de dicha regla, entonces la regla está mal formulada y hay que reformularla.

Estamos conscientes de que siempre se puede encontrar otra excepción, hasta tratar de acabar centrándonos en todos los actos, lo cual considero es poco plausible, ya que al ser seres imperfectos es una tarea titánica y casi imposible tratar de prever todos los supuestos de hechos de la excepción a las reglas; pero si evadimos una regla por sus casos de excepción, acabamos transformándonos en utilitaristas de actos.

Como se mencionó al inicio, una regla que contenga excepciones no la hace menos perfecta, sino que estas la amplían y la perfeccionan. También se está consciente de que el hecho de inobservar la regla (en algunas ocasiones), produce una disminución de la felicidad que debe tomarse en consideración, pero no se está pidiendo un cálculo exacto, sino una búsqueda pru- dente, sensata y razonable de la felicidad en general. ${ }^{28}$

Es una realidad indiscutible que muchas veces es mejor incumplir una regla que seguirla, puesto que realizar lo contrario nos volvería un adorador o fanático de la misma, siendo más que plausible y necesario optar por el utilitarismo de actos, pues lo que debemos valorar son las consecuencias de la acción.

Así, se considera plantear y responder las siguientes interrogantes que pueden surgir:

1. Entonces, ¿qué finalidad tiene una regla que no debe ser seguida? Una regla ha sido creada para que la actuación de las personas no contradiga lo que se estipula; que existan excepciones a la misma no la vuelve imperfecta o inválida.

2. ¿Cuál es el fundamento que permite la excepción a la regla? La respuesta creemos que ya la resolvió la profesora Guisán (2000) al mencionar que:

Cuando está claro que unos bienes son superiores a otros en lo que a la producción del goce profundo y solidario se refiere, las consideraciones cuantitativas son irrelevantes. Una sola persona feliz en su libertad es preferible a un millón

28 Álvarez Gálvez, Îñigo, La desviación de J. S. Mill: el puesto de las emociones en el utilitarismo, Revista Iberoamericana de Estudios Utilitaristas, vol. 17, núm. 2, 2010, pág. 162 (https://goo.gl/e8tCVd); fecha de consulta: 1 de febrero de 2019. 
de seres felices en su esclavitud o su servidumbre;

como podemos apreciar, la respuesta está basada en supuestos morales, en la justicia, apartando a un lado la utilidad.

\section{La propuesta de John Stuart Mill respecto a la justicia y los derechos}

Mencionamos al principio del presente trabajo que el problema que nos ocupa es dilucidar la posibilidad de reconciliar la doctrina utilitarista con los DD. HH. Presentar una teoría moral -que no de justificación a la justicia- sería menos que inservible; el punto de inflexión es que, al parecer, en la corriente utilitarista la justicia no tiene cabida, porque el utilitarismo tiene en la mira a la utilidad general, y la justicia se desliga de esta utilidad general. ${ }^{29}$

Es correcto afirmar que la utilidad general se desliga de la justicia, porque sabemos que esta no va asociada a la arbitrariedad y actúa de manera equitativa, tratando por igual a todos los ciudadanos con independencia de su raza, sexo, condición sexual, origen... vale decir que todos somos iguales ante la ley, al menos así lo menciona el artículo primero de la Constitución de los Estados Unidos Mexicanos. ${ }^{30}$

29 Álvarez Gálvez, İñigo, op. cit., nota 6, pág. 317.

30 Artículo 10. En los Estados Unidos Mexicanos todas las personas gozarán de los derechos humanos reconocidos en esta Constitución y en los tratados internacionales de los que el Estado Mexicano sea parte, así como de las garantías para su protección, cuyo ejercicio no podrá restringirse ni suspender-
John Stuart Mill entiende que la justicia proviene de lo justo. ¿Qué es lo justo?, lo que debe estar de conformidad con la ley; Mill concluye que la idea de la observancia de la ley tiene que ver con el núcleo de concepto de justicia. Acorde con lo anterior, de la mano con la justicia va enlazado un sentido del deber. La justicia es aquello que es correcto hacer e incorrecto no hacer, pero no únicamente esto, sino que también lleva implicado un derecho correlativo por otra persona que puede exigir como su derecho moral. ${ }^{31}$

John Stuart Mill nos menciona que el concepto de justicia no tiene nada que ver con la conveniencia general (entendida como aquello que tenga la propiedad para ser útil, conveniente o provechoso para la generalidad); aunque llega a haber una relación con la conveniencia general, debido a lo moral que lleva consigo implícito el concepto de justicia.

Nos menciona que el sentimiento de justicia tiene que ver con el deseo de castigar a alguien, porque ha hecho daño a otro; este sentimiento de castigar a otro, si bien es cierto no es moral, se reviste de esta característica debido a la simpatía social, que es la capacidad que tenemos las personas de sentirnos ofendidas por el daño hecho a otras, aunque no lo hayan sentido en carne propia, pero no cualquier daño que puedan ocasionar será considerado

se, salvo en los casos y bajo las condiciones que esta Constitución establece.

31 Cfr. Ibidem, pág. 319. 
como una afrenta, pues debe ser del tipo que la sociedad tiene interés en reprimir.

Dice Mill: "Tener un derecho, por tanto, es entiendo, tener algo en cuya posesión la sociedad debe defenderme. Si el objetante continúa preguntando por qué debe, no puedo darle otra razón que la utilidad general"; ${ }^{2}$ en consecuencia, cada individuo debe respetar y hacer valer los derechos, porque al hacerlo de esa forma es como se alcanza la felicidad general, de manera tal que los derechos no entran en conflicto con la consecución de la felicidad general, sino que son parte de ella. ${ }^{33}$

Mill se pronuncia respecto a la justicia de la siguiente manera, por lo que me permito citar textualmente el pensamiento del autor:

To recapitulate the idea of justice supposes two things; a rule of conduct, and a sentiment which sanctions the rule. The first must be supposed common to all mankind and intended for their good. The other (the sentiment) is a desire that punishment may be suffered by those who infringe the rule. There is involved, in addition, the conception of some definite person who suffers by the infringement;

32 Cfr. Ibidem, pág. 321.

33 Álvarez Gálvez, İnigo, La desviación de J. S. Mill: el puesto de las emociones en el utilitarismo, Revista Iberoamericana de Estudios Utilitaristas, vol. 17, núm. 2, 2010, pág. 162 (http://www.usc.es/revistas/index. php/telos/article/download/768/750); fecha de consulta: 12 de noviembre de 2018. whose rights (to use the expression appropriated to the case) are violated by it. ${ }^{34}$

La justicia tiene que ver con la obligación de hacer algo, que crea el derecho de otra persona a exigir que ese hacer por parte de nosotros sea realizado; es decir, se le exige a la sociedad que ese derecho debe ser respetado o protegido.

Las reglas o los derechos son útiles, porque ayudan a alcanzar la felicidad o el mayor bienestar general, o dicho de otra manera, puesto que lo que se procura es alcanzar la felicidad general, se elaboran determinadas reglas que nos ayudan a decidir y comportarnos.

Poseer un derecho por el cual las personas deben defenderlo por razón de una utilidad general, se traduce o se interpreta en que aquel va a desencadenar una felicidad general. ${ }^{35}$ ¿Por qué va a desencadenar

34 Traducción personal: "La idea de justicia supone dos cosas: una regla de conducta y un sentimiento que sanciona la regla. El primero debe suponerse común a toda la humanidad, y destinado a su bien. El otro (el sentimiento) es un deseo de que los que infringen la regla puedan sufrir un castigo. Se trata, además, de la concepción de alguna persona definida que sufre por la infracción, cuyos derechos (para usar la expresión apropiada para el caso) son violados por ella”. Cfr. Mill, John Stuart, Utilitarianism and the 1868 Speech on Capital Punishment, $2^{\text {nd }}$ Ed., Hackett Publishing Company, Inc., pág. 53.

35 John Rawls en su obra Teoría de la justicia del año 1972 menciona que son los bienes que se pueden suponer deseables para todo ser humano racional, sean cuales sean los deseos más particulares de tal ser humano. Son los bienes que resultan útiles, sea cual sea el plan de vida racional mantenido por una determinada persona concreta.

Como podemos apreciar, John Rawls es un utilitarista contemporáneo del siglo xx. La única diferencia de Rawls con los utilitaristas anteriores, es que 
una felicidad general? La respuesta es sencilla si encontramos el hilo conductor de todo lo expuesto: si el sentimiento de simpatía por otros está tan bien desarrollado, entonces la felicidad del individuo singular depende del bienestar de los otros.

Así también lo ha expresado Esperanza Guisán (2000) ${ }^{36}$ —filósofa utilitarista contemporánea-:

Concebido así el ser humano no sólo como un ser que se interesa por los demás, sino con capacidad de gozar ayudando a los demás a que se desarrollen libremente, las cautelas individualistas de la concepción predominante parecen carecer de sentido.

Lo que han tratado de enunciar Mill y Guisán (2000), es que hay intereses individuales cuya importancia es tal que su satisfacción es prioritaria para incrementar el bienestar; por ello, el interés en preservarlos mediante una regla de conducta general de aplicación simple ha de prevalecer necesariamente sobre cualesquiera otros en un razonamiento utilitarista y justifica

no prioriza la felicidad general como una meta o goal, sino que los bienes básicos o primarios y los derechos humanos per item, permiten a cada uno de los individuos alcanzar la felicidad — cada quien concibe la felicidad desde su punto de vista; dicho de otra manera, sin importar subrepticiamente el concepto de felicidad que cada quien posea.

36 Esperanza Guisán Seijas fue una filósofa, catedrática universitaria y ensayista española, reconocida por haber sido la introductora del utilitarismo contemporáneo en España y difusora de una ética informada por la justicia, la felicidad y el bienestar. defenderlos como derechos, prescindiendo del cálculo de utilidad inmediato.

Podemos resumir lo anterior de la siguiente manera:

1. 1. Poseer un derecho es tener algo cuya posesión debe garantizar la sociedad.

2. Si cualquier objetante me pregunta por qué lo debe defender la comunidad, se debe responder que es debido a la utilidad general.

3. Si la respuesta a la pregunta: ¿por qué debe defender mis derechos?, no parece indicar con intensidad suficiente la fuerza de la obligación ni explicar la energía peculiar del sentimiento, es porque en la composición de este último entra no solo un elemento racional, sino también uno animal: la sed de la represalia; y la intensidad de esta, lo mismo que la justificación moral, se derivan de la clase de utilidad extraordinariamente importante e impresionante a que se refieren.

4. El sentimiento de simpatía por otros está tan bien desarrollado que la felicidad del individuo depende del bienestar de los otros.

5. La justicia que propone John Stuart Mill nos lleva a aceptar el utilitarismo que defiende y se asocia con los derechos.

6. El interés que entrañan los derechos es el de la seguridad, que ante los sentimientos de cada uno es el más importante de todos los seres humanos. 
7. Sabemos — diríamos-que siguiendo esas reglas, es como se alcanza la felicidad general.

Apoyándonos en Massini Correas, sostenemos que es imposible pensar en los derechos sin admitir un necesario deber jurídico de otro/s sujeto/s jurídico/s, por lo que el hecho de que si este o estos sujetos deudores son a veces difícilmente determinables ${ }^{37}$ no argumenta absolutamente nada en contra de esta afirmación. Sin esta correlatividad, los intereses que buscan protección pueden pasarse sin ellos, ya que no habrá otra persona por cuya responsabilidad pueda quedar obligado. ${ }^{38}$

Lo anterior lo podemos reafirmar y conjugar con la Teoría de los derechos subjetivos, pues sería de una ignorancia enciclopédica no concebirlos así, pues se afirma, sin mayor vacilación, que los derechos no deben ser reconocidos, sino únicamente tutelados; que deben existir las garantías para que estos sean protegidos. En este sentido, y como consecuencia lógica de lo anteriormente manifestado, los DD. HH. deben y pueden ser concebidos como subjetivos, que son tradicionalmente pasibles de ser tutelados por vía judicial.
De manera sumaria podemos advertir que los DD. HH. son una clase de derechos subjetivos. Este argumento lo vamos a concatenar con la positivización de los DD. HH., para que se conviertan en fundamentales, pues si estamos partiendo de que los DD. HH. son una clase de derechos subjetivos, sería un absurdo no mencionar que están vinculados al derecho positivo.

Ser titular de un derecho supone la existencia de una facultad para ejercerlo; ya se han pronunciado diversos autores de enorme relevancia respecto a lo que se entiende por derecho subjetivo. Podemos mencionar a Ferrajoli (2001), quien expresa lo siguiente: "Cualquier expectativa positiva (de prestaciones) o negativa (de no sufrir lesiones) adscrita a un sujeto por una norma jurídica”. ${ }^{39}$ El profesor Rolando Tamayo y Salmorán se ha pronunciado manifestando que:

[...] el derecho subjetivo contiene la autorización conferida al derechohabienteal titular del derecho (o a quien actúe en su nombre)—, de dirigirse al órgano de aplicación (i.e. el tribunal) requiriendo, mediante la interposición de una demanda o acción, la ejecución de su derecho...40

39 Ferrajoli, Luigi, Los fundamentos de los derechos fundamentales, Madrid, Trotta, 2001, pág. 19.

40 Tamayo y Salmorán, Rolando, El derecho y la ciencia del derecho. Introducción a la ciencia jurídica, México,

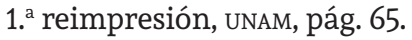


Lo anterior refuerza nuestra postura inicial de alejarnos de la fundamentación naturalista de los DD. HH. y fortalecer nuestra postura con el fundamento historicista y positivista de los mismos.

\section{El utilitarismo como medio para solucionar los conflictos normativos a nivel constitucional}

Seguir o acatar las reglas va encaminado a una utilidad, por lo que se piensa que es provechoso seguirlas, aunque nunca harán falta cuestiones en las que se plantee un problema particular en relación con un aparente conflicto de normas, las cuales reconocen derechos, y en esos casos, estos derechos parecerían ser contradictorios o incompatibles. Como afirma Îñigo Álvarez:

Por otro lado, estas reglas que son los derechos pueden tener, como todas, determinadas excepciones. Puesto que están pensadas con el fin de promover la felicidad general, la constatación en un caso dado de una disminución grave de la tal felicidad general puede hacer que se deje de lado la regla. O dicho de otro modo, puesto que lo que se pretende es conseguir la felicidad general, se elaboran determinadas reglas que nos ayudan a decidir y comportarnos (sabemos, diríamos, que siguiendo esas reglas es como se alcanza la felicidad general); pero, a la vez, puesto que lo que pretendemos es conseguir la felicidad general, cuando comprobamos que siguiendo tales reglas lo que se consigue es disminuirla gravemente, el mismo fin nos indica que debemos dejar de lado las tales reglas. ${ }^{41}$

Podemos enunciar algunos ejemplos donde existe un aparente conflicto de los DD. HH.:

1. En el caso del aborto: el derecho a la vida del niño; y el derecho a la libertad y al libre desarrollo de la personalidad de la madre.

2. En el consumo de drogas: el derecho a la libertad, al libre desarrollo de la personalidad y la privacidad del drogadicto; y el derecho a la salud pública y seguridad de la población.

3. En la pornografía: el derecho a la libertad de expresión y privacidad frente al derecho a la moral pública, la defensa de la familia y la sana educación de los niños y jóvenes.

4. En los noticieros: el derecho a la libertad de expresión frente al derecho al honor y la intimidad.

5. En la clonación de seres humanos: el derecho a la reproducción frente al derecho a la dignidad y la vida del embrión.

Y la cuenta o enumeración de una aparente colisión o conflicto de DD. HH. podría seguir. ¿Cómo solucionar este dile-

41 Álvarez Gálvez, İñigo, op. cit. 
ma? Un utilitarista del acto realizaría un cálculo de beneficios y perjuicios del principio que subyace tras los actos, es decir, ponderaría los beneficios y perjuicios de seguir o no una regla u otra; un utilitarista de reglas debe aplicarlas sin importar las consecuencias, pues para él es benéfico emplearlas sin tomar en cuenta las consecuencias de su aplicación, pero el utilitarismo de reglas debe concebir que los DD. HH. no están estructurados como una norma habitual y no siguen la lógica de todo o nada, por lo que al estar ante una aparente colisión de DD. HH. debe, al finalizar, ponderar con base en un utilitarismo de actos, si beneficia más seguir una regla u otra. ¿Cuáles DD. HH. brindarán más beneficio o felicidad?; o también acercándolo al pensamiento de Robert Alexy (2008): "Cuanto mayor es el grado de la no satisfacción de uno de los principios, tanto mayor debe ser la importancia de la satisfacción del otro".

¿Por qué un derecho no debe ser satisfecho y otro sí? No estamos, entonces, reduciendo la ponderación del jurista alemán a un cálculo utilitarista. La respuesta es obvia y afirmativa. Claramente es benéfico aplicar el utilitarismo y resulta imposible no aplicar consciente o inconscientemente cierto grado y tipo de utilitarismo en la ponderación de los DD. HH.

El utilitarista de reglas se basa en que al respetar los derechos, se genera una mayor felicidad, pero muchas veces seguir la regla general conlleva más infelicidad que felicidad, por lo que concurren casos de excepción; entonces, al ponderar los DD. HH., vemos que se aplica un utilitarismo de actos y no de reglas, puesto que el utilitarista valora las consecuencias que se generan en la aplicación de un derecho o de otro.

¿Qué hace un defensor de los DD. HH. ante una "colisión" de estos? En este punto me gustaría hacer mención de que los DD. HH. no pueden cumplirse siempre o hacerse valer; esa característica de que siempre tienen que ser cumplidos, puede verse opacada cuando un derecho humano tenga que dejar de ser aplicado para que otro se respete.

Mantener la postura contraria a lo anteriormente manifestado, sería un amor exacerbado por las reglas; así lo comenta Smart: “(...) afirmar que hay reglas que deben ser obedecidas aun en los casos en los que es evidente que no es la vía para producir la máxima felicidad es caer en la adoración a la regla". ${ }^{42}$ Como plantea John Stuart Mill acerca de que el respeto a los derechos, es un deber de justicia, pero en determinados casos lo justo es no respetarlos.

También existen otras situaciones independientes a una "colisión" de DD. HH., como casos en los que los derechos pueden ser inobservados debido a extremas situaciones que demandan un mayor bienestar

42 Citado por Álvarez Gálvez, Înigo, Utilitarismo y derechos humanos: la propuesta de John S. Mill, Madrid, Plaza y Valdés, 2009, pág. 98. 
general. Así, incluso, lo establece el artículo 29 constitucional. ${ }^{43}$

Es obvio que al contar con derechos también existen límites para ellos, lo que nos lleva a considerar que nuestros derechos pueden llegar a ser desplazados por otros. De la idea esbozada anteriormente, se puede perfilar el caso de una "colisión" de derechos del mismo rango y, a la vez, la consecuencia inevitable de ponderarlos.

Como sabemos, la incorporación de los DD. HH. en nuestro ordenamiento jurídico los ha positivizado, es decir, les ha dado legalidad, ${ }^{44}$ convirtiéndolos así en derechos fundamentales, pero de su positivización no se sigue que hayan perdido su estructura lógica de principios, pues estos están enunciados de diversa forma que las normas o reglas.

Los DD. HH. incluidos en nuestra Constitución y en otras, están redactados como

43 "En los casos de invasión, perturbación grave de la paz pública, o de cualquier otro que ponga a la sociedad en grave peligro o conflicto, solamente el presidente de los estados unidos mexicanos, de acuerdo con los titulares de las secretarias de estado, los departamentos administrativos y la procuraduría general de la república y con aprobación del congreso de la unión, y, en los recesos de este, de la comisión permanente, podrá suspender en todo el país o en lugar determinado las garantías que fuesen obstáculos para hacer frente, rápida y fácilmente a la situación; pero deberá hacerlo por un tiempo limitado, por medio de prevenciones generales y sin que la suspensión se contraiga a determinado individuo....".

44 Todo ello puso en jaque al positivismo jurídico tradicional, que consideraba al derecho como tal en tanto y en cuanto este fuera formalmente válido y eficazmente vigente conforme a los principios de validez y eficacia, los cuales fueron en gran parte establecidos por Hans Kelsen. Cfr. Kelsen, Hans, Teoría pura del derecho, Buenos Aires, Eudeba, 1974, pág. 142. principios; en la actualidad se concibe que los sistemas jurídicos están formados no únicamente por reglas, sino también por principios capaces de dirigir la acción como un derecho directamente aplicable.

Robert Alexy (2008) manifiesta puntualmente que los principios son: “(...) normas que ordenan que algo sea realizado en la mayor medida posible, dentro de las posibilidades jurídicas y realidades existentes" ${ }^{45}$ Una característica de los principios es que pueden cumplirse en diferente grado y porque la medida debida de su cumplimiento no solo depende de las posibilidades reales, sino de las jurídicas. El mejor ejemplo de los principios son los derechos fundamentales incluidos en nuestra Constitución Política.

Lo anterior básicamente cae en el supuesto a considerar cuando un derecho es apartado por otras consideraciones, que tendrán que estar fundamentadas o sustentadas sobre la base de las consecuencias que se producirán, es decir, qué consecuencias puede llevar si se respeta tal derecho en cuestión. Podríamos decir que alguien que defienda los DD. HH., va a negar la libertad de expresión a quien colabore con personas cuyos actos resulten flagrantemente en contra de los derechos de otras; en este caso podríamos mencionar a aquel que colaborara con el régimen nazi.

45 Alexy, Robert, Teoría de los derechos fundamentales, Madrid, Centro de Estudios Políticos y Constitucionales, 2008, pág. 67. 
Es obvio que en el caso anterior, mantener una postura de respetar el derecho anterior o ciertos derechos conlleva a todo lo contrario que busca el utilitarismo, es decir, acarrea una mayor infelicidad. En este caso, el principio de la utilidad opera de dos maneras; el mismo principio que nos obliga a respetar los derechos por el beneficio de todos y una mayor felicidad, lleva consigo mismo también que no respetemos ese derecho, para así evitar una gran infelicidad y, al mismo instante, se produzca mucha felicidad.

Lo inconveniente de este tipo de utilitarismo es la medición que se hace respecto a la felicidad en grados que se pretende buscar; asimismo, no sabemos qué criterios se utilizaron para poder valorar y llegar a tal medición. La objeción más importante es que el derecho quedaría en un segundo plano, puesto que solo se respetaría mientras genera una mayor felicidad, es decir, seguiría la suerte de lo principal porque serían accesorios. Lo que caracterizaría al derecho, entonces, sería la utilidad y no el derecho per se.

Igualmente, este tipo de utilitarismo parece no reconocer el carácter primario de los DD. HH., porque no los coloca como ejes motores en sí, sino que los derechos resultan ser una consecuencia de la aplicación del principio de utilidad. Ahora, respondiendo la pregunta del apartado vi intitulado: ¿Es posible conciliar la idea del utilitarismo con los derechos humanos?, la respuesta es afirmativa.

Si bien los DD. HH. ya se encuentran positivizados en una norma siguen desempeñándose con la mecánica de los principios. Desde el punto de vista del defensor de los DD. HH., al decir que un derecho no puede ser violado significa que se le concede un determinado peso; lo mismo que al decir que tiene límites significa que se le reduce dicho peso. Eso es lo que hace también el utilitarista: conceder un peso determinado al derecho para realizar el cálculo.

Esto es lo que nos indica a la postre si en una determinada situación debe prevalecer un derecho o no; es lo que nos indica el peso que debemos asignarle, y quizá no sea descabellado pensar que el defensor de los derechos no puede escapar de estas consideraciones.

Me gustaría hacer una distinción entre las reglas o normas y así también una pequeña distinción entre estas y los principios. Se dice que estos últimos se caracterizan por su formulación, su estructura lógica o su contenido; otros sostienen que se destacan por la posición que ocupan en el ordenamiento jurídico o por la función que cumplen en él. ${ }^{46}$

Se ha intentado realizar una distinción entre cinco variables distintas entre reglas y principios:

46 Cárdenas Gracia, Jaime, La argumentación como derecho, México, 2. ${ }^{\mathrm{a}}$ ed., Instituto de Investigaciones Jurídicas, 2007, pág. 111. 
a) Las disposiciones que expresan principios son formuladas en un lenguaje extremadamente fluido, vago, indeterminado.

b) Una segunda tesis pretende caracterizar a los principios por su contenido normativo. Son más generales y, más que dirigirse a los comportamientos, se dirigen a las actitudes.

c) La tercera vía señala que los principios no tienen la estructura lógica de las reglas. Son normas categóricas (no están ligadas a una condición) que están privadas de un ámbito específico de aplicación.

d) Se distinguen los principios en virtud de su carácter de normas fundamentales (fundamento de otras normas) y porque dan identidad material al ordenamiento en su conjunto.

e) En una quinta aproximación, se indica que los principios no admiten la interpretación literal; tienen un carácter orientador respecto a las reglas; no es posible la aplicación por subsunción en los principios; y los conflictos entre principios, se resuelven con la técnica de la ponderación. ${ }^{47}$

De lo anterior, podemos llegar a decir que, respecto a los DD. HH. (que en su estructura fungen como principios), no se puede llegar a una única respuesta correcta en la solución de resultados jurídicos

47 Idem. complicados en la cual haya una aparente colisión de derechos.

Con los principios no se aplica la regla que caracteriza a las reglas, es decir, no tienen un carácter concluyente de todo o nada. Aunado al hecho de que no funcionan con la subsunción de los hechos a la norma, por lo consiguiente tendrá que resolverse por la ponderación; ponderar es básicamente pesar un principio como si se pudiera colocar en el plato de una balanza.

Algunas personas sostienen que el utilitarismo es contrario a los DD. HH., porque son universales y absolutos, pero es sabido que en muchas ocasiones son inaplicados porque existe una ponderación entre ellos. Lo anterior no significa que uno sea vencido o derrotado, puesto que, como ya sabemos, los DD. HH. tienen la estructura de los principios y no de las reglas. Así, ponderar un derecho es una cuestión de grados; cuál debe prevalecer en esa situación y cuál no, no hace inválido ese derecho humano. Así, los DD. HH. no quedan sacrificados o desplazados.

La Ley de Ponderación de Robert Alexy (2008) reza de la siguiente manera: "Cuanto mayor es el grado de la no satisfacción de uno de los principios, tanto mayor debe ser la importancia de la satisfacción del otro". Como se puede observar, Alexy usa la palabra satisfacción, que es un sentimiento de bienestar o placer que se tiene cuando se ha colmado un deseo o cubierto 
una necesidad. La Ley de Ponderación se puede definir en tres momentos:

1. En el primer paso es preciso definir el grado de la no satisfacción de uno de los principios.

2. Se define la importancia de la satisfacción del principio que juega en sentido contrario.

3. Debe definirse si la importancia de la satisfacción del principio contrario justifica la afectación o no afectación del otro. ${ }^{48}$

Ya lo mencionó Dworkin (2012) al afirmar que los principios tienen una dimensión de peso e importancia, debido a que cuando los principios se enfrentan quien debe resolver el conflicto tiene que calcular el contrapeso relativo de cada uno. ${ }^{49}$ Lo encantador de este planteamiento, es que desde el punto de vista de John Stuart Mill no se encuentra tan alejado de lo que se puede defender desde una teoría de los derechos y, en particular, de los DD. HH.

Se ha visto que es posible también desde una teoría de los derechos en donde se parta de la premisa de que estos tienen un carácter absoluto de los DD. HH., lo cual

48 Cfr. Bernal Pulido, Carlos, Estructuray límites delaponderación, España, Doxa, 1989, págs. 8 y 9 (http://publicaciones.ua.es/filespubli/pdf/02148676RD49949854. pdf); fecha de consulta: 27 de diciembre de 2018.

49 Cfr. Dworkin, Ronald, Los derechos en serio, España, Ariel, 2012, pág. 77. es en realidad relativo a las situaciones. ${ }^{50}$ También, desde este punto de vista, la defensa de los derechos se apoya en último extremo en su bondad, y, en fin, también cabe afirmar que las limitaciones y las aboliciones de ciertos derechos, se sostienen en función de las consecuencias.

\section{Conclusiones de un no escéptico a la conciliación del utilitarismo y los derechos humanos}

Esta investigación conlleva a afirmar que aplicar el utilitarismo a los DD. HH. no solo es útil, sino que resulta imposible dejar de hacerlo en los "conflictos" suscitados entre los DD. HH.

1. El utilitarismo permite decidir en materia de conflictos jurídicos, razón por la cual sí es posible asociar esta doctrina ética con los DD. HH.

2. Es posible asociar el utilitarismo y los DD. HH., incluso a partir de la Teoría de los derechos en donde se parta de la premisa de que estos tienen un carácter absoluto, pero haciendo la aclaración de que en realidad es relativo a las situaciones.

3. Los DD. HH. son aplicados con base en un utilitarismo de actos y no de reglas, toda vez que su estructura no tiene la

50 Cfr. Álvarez Gálvez, İñigo, Una fundamentación utilitarista de los derechos humanos: J. S. Mill, pág. 6 (http://www.uv.es/cefd/15/alvarezgalvez.pdf); fecha de consulta: 27 de diciembre de 2018. 
forma como una norma habitual, es decir, no sigue la lógica de todo o nada, por lo que al estar ante una aparente colisión de DD. HH., debe, al finalizar, ponderar con base en un utilitarismo de actos y no de reglas.

4. Los beneficios utilitarios que se aplican a los DD. HH. coinciden con las razones principales por las que se han desarrollado los sentimientos hacia ellos.

5. Los filósofos utilitaristas justifican proteger los DD. HH. por la utilidad que reportan.

6. Mill y otros filósofos —entre ellos, Guisán (2000)_ postulan en sus obras una interpretación del cálculo utilitario que es razonable, el cual se amolda armónica y teleológicamente a los DD. HH.

7. En relación con los conflictos suscitados entre los DD. HH., no se puede llegar a una única respuesta correcta en la solución de resultados jurídicos en la cual haya una colisión de los mismos, por lo que en algunas ocasiones va a prevalecer uno sobre otro, pero jamás desaparecerán.

8. El utilitarismo busca maximizar la felicidad y los derechos son reglas que apuntan a la maximización de la felicidad.

9. Como ya mencionó John Rawls (1972) en su obra Teoría de la justicia, los bienes básicos/primarios son equivalentes a los DD. HH. que conocemos hoy en día.
10. El presente estudio que se ha abordado seguramente es un resumen demasiado simplificado de la fundamentación utilitarista articulada junto con los DD. HH., pero de lo contrario sería una tarea titánica, ya que son posibles otros desarrollos, combinaciones y matices.

11. Los llamados conflictos entre los derechos fundamentales solo pueden ser aparentes y deben tener un nombre, pero realmente es inexistente un conflicto entre ellos.

\section{x. Bibliografía}

Audi, R. (1999). The Cambridge Dictionary of Philosophy (2. ${ }^{\text {a }}$ Ed.). England: Cambridge University Press.

Alexy, R. (2008). Teoría de los derechos fundamentales. Madrid: Centro de Estudios Políticos y Constitucionales.

Álvarez Gálvez, Ĩñigo (2009). Utilitarismo y derechos humanos: la propuesta de John $S$. Mill, Madrid: csic/Plaza y Valdés.

Aristóteles (2010). Ética nicomaquea (22. ${ }^{\mathrm{a}}$ ed.). México: Porrúa.

Beccaria, C. (1988). De los delitos y de las penas (trad.: Juan Antonio de las Casas). Madrid: Editorial Alianza.

Bentham, J. The Philosophy of Economic Science - The Psychology of Economic Man. London: The Royal Economic Society by George Allen \& Unwin Ltd.

Bernal Pulido, C. (1989). Estructura y límites de la ponderación. España: Doxa. 
Cárdenas Gracia, J. (2007). La argumentación como derecho (2. ${ }^{a}$ ed.). México: Instituto de Investigaciones Jurídicas.

Cortina, A. (2010). Justicia cordial. España: Trotta.

Dworkin, R. (2012). Los derechos en serio. España: Ariel.

Ferrajoli, L. (2001). Los fundamentos de los derechos fundamentales. Madrid: Trotta.

González Amuchastegui, J. (2004). Autonomía, dignidad y ciudadanía: una teoría de los derechos humanos. España: Tirant Lo Blanch.

Guisán, E. (2000). Más allá de la democracia. Madrid: Tecnos.

Kelsen, H. (1974). Teoría pura del derecho. Buenos Aires: Eudeba.

Marx, K. (1976). Capital (trad.: Ben Fowkes). England: Penguin Classics.

Massini Correas, C. (2005). Filosofía del derecho. Tomo I. El derecho, los derechos humanos y el derecho natural. Buenos Aires: LexisNexis/Abeledo-Perrot.

Rodríguez-Toubes Muñiz, J. (2010). La utilidad de los derechos humanos. Revista Iberoamericana de Estudios Utilitaristas, 17(2).

Tamayo y Salmorán, R. El derecho y la ciencia del derecho: introducción a la ciencia jurídica (1. ${ }^{\text {a }}$ reimp.). México: unAm.

\section{Cibergrafia}

Álvarez Gálvez, Î. (2014). Universales, absolutos e inalienables: los derechos indestructibles. Revista de Humanidades de
Valparaíso, 4, año 2. Recuperado de https://goo.gl/k1dxtj.

----.. Una fundamentación utilitarista de los derechos humanos: J. S. Mill, p. 6. Recuperado de http://www.uv.es/cefd/15/ alvarezgalvez.pdf

Kant, I. Fundamentación de la metafísica de las costumbres. Recuperado de http://pmrb. net/books/kantfund/fund_metaf_costumbres_vD.pdf

Moreno Doña, A. Una mirada crítica a la ética pragmática de Richard Rorty desde la propuesta ética de Humberto Maturana. A Parte Rei. Revista de Filosofía, 34. Recuperado de http://serbal.pntic.mec. es/ cmunoz11/moreno34.pdf

Pérez Triviño, J. L. (2004). La noción rawlsiana de autorrespeto. Diritto eə Questioni Pubbliche, 4. Recuperado de http://www.dirittoequestionipubbliche.org/page/2004_ n4/studi_I_Perez-Trivino.pdf

Valcarce, A. El utilitarismo y la Teoría moral de Adam Smith. Revista Empresa y Humanismo, 13(1/10), 271. Recuperado de https://goo.gl/m8hnJS

Varó Peral, Á. Algunas teorías éticas occidentales. Asignatura: Ética $4 t$ ESO. Recuperado de https://www.nodo50.org/filosofem/IMG/pdf/etica4c.pdf 